\title{
PROJECTIONS AND IDEMPOTENTS WITH FIXED DIAGONAL AND THE HOMOTOPY PROBLEM FOR UNIT TIGHT FRAMES
}

\author{
Julien Giol, LeOnid V. Kovalev, DaVid LaRson, \\ NGa NGuYen AND JAMES E. TENER
}

Abstract. We investigate the topological and metric structure of the set of idempotent operators and projections which have prescribed diagonal entries with respect to a fixed orthonormal basis of a Hilbert space. As an application, we settle some cases of conjectures of Larson, Dykema, and Strawn on the connectedness of the set of unit-norm tight frames.

Mathematics subject classification (2010): 47A05, 47L35, 47L05.

Keywords and phrases: Projection, idempotent, normalized tight frame, diagonal, connected, paving.

\section{REFERENCES}

[1] J. J. Benedetto And M. Fickus, Finite normalized tight frames, Adv. Comput. Math., 18, 2/4 (2003), 357-385.

[2] P. Casazza, D. Edidin, D. Kalra And V. Paulsen, Projections and the Kadison-Singer problem, Matrices and Operators, 1, 3 (2007), 391-408.

[3] P. CasazZa And J. KovaČEvić, Equal-norm tight frames with erasures, Adv. Comput. Math., 18, 2-4 (2003), 387-430.

[4] E. M. Chirka, Complex analytic sets, Kluwer Acad. Publ., 1989.

[5] K. Dykema, D. Freeman, K. Kornelson, D. Larson, M. Ordower and E. Weber, Ellipsoidal tight frames, Illinois J. Math., 48 (2004), 477-489.

[6] K. Dykema And N. Strawn, Manifold structure of spaces of spherical tight frames, Int. J. Pure Appl. Math., 28, 2 (2006), 217-256.

[7] V. K. GoYal, J. KovaČEviĆ And J. A. Kelner, Quantized frame expansions with erasures, Appl. Comput. Harmon. Anal., 10 (2001), 203-233.

[8] P. R. Halmos, Two subspaces, Trans. Amer. Math. Soc., 144 (1969), 381-389.

[9] D. HAn, K. Kornelson, D. LARSOn AND E. Weber, Frames for Undergraduates, AMS Student Mathematical Library, vol. 40, 2007.

[10] D. Han And D. Larson, Frames, bases and group representations, Mem. Amer. Math. Soc., 147, 697 (2000).

[11] R. V. Kadison, The Pythagorean theorem. I. The finite case, Proc. Natl. Acad. Sci. USA, 99, 7 (2002), 4178-4184.

[12] R. V. Kadison, The Pythagorean theorem. II. The infinite discrete case, Proc. Natl. Acad. Sci. USA, 99, 8 (2002), 5217-5222. 
[13] N. H. KUIPER, The homotopy type of the unitary group of Hilbert space, Topology, 3 (1965), 19-30.

[14] D. R. LARSON, Nest algebras and similarity transformations, Ann. of Math. (2), 121, 3 (1985), 409427.

[15] D. R. LARSON, Unpublished REU seminar course notes, Summer 2002.

[16] T. STROHMER AND R. W. HeATH JR., Grassmannian frames with applications to coding and communication, Appl. Comput. Harmon. Anal., 14, 3 (2003), 257-275. 